\title{
Отдаленные результаты эндопротезирования брюшного отдела аорты. Можно ли рассчитывать на долгосрочный результат?
}

\author{
Фуркало С. Н., Никульников П. И., Хасянова И. В., Власенко Е. А. \\ Национальный институт хирургии и трансплантологии им. А. А. Шалимова НАМНУ, г. Киев, Украина
}

\begin{abstract}
Резюме. Работа посвящена анализу отдаленных результатов эндопротезирования брюшного отдела аорты у пациентов с аневризмой абдоминального отдела. Отмечены позитивные 10-летние результаты наблюдения, динамика аневризматического мешка после вмешательства, изучена необходимость в повторных эндоваскулярных вмешательствах, а также их особенности и показания. Представлены результаты морфологических исследований стенки аорты и связь их со стабильностью аневризматического мешка.
\end{abstract}

Ключевые слова: аневризма брюшного отдела аорты, эндопротезирование аорты, динамика аневризматического мешка, морфология сосудистой стенки, эндопротекания.

Вступление. Эндопротезирование брюшного отдела аорты является приоритетным методом лечения аневризм брюшного отдела аорты. Однако малая операционная инвазивность и травматичность частично нивелируется необходимостью в большей частоте повторных оперативных вмешательств в отдаленный период наблюдения [1] и, по некоторым данным, увеличенной частотой аневризм-связанной смертности $[2,3,4]$. В то же время постоянное совершенствование эндоваскулярного оснащения и технологических подходов не позволяет в полной мере экстраполировать результаты, полученные во время применения более ранних технологий, на современные возможности [5].

В работе представлен анализ отдаленных результатов эндоваскулярного лечения аневризм инфраренального отдела аорты у 110 больных, которым были имплантированы стент-графты в инфраренальную позицию с ноября 2005 по сентябрь 2016 года.

Цель исследования. Проследить отдаленные результаты эндопротезирования брюшного отдела аорты, определить возможность прогнозирования результата и предложить варианты коррекции возникающих осложнений.

Материалы и методы. Средний возраст больных составил 68,5 \pm 9,8 года, 104 пациента были мужского пола. Артериальная гипертензия, требующая медикаментозного лечения, была отмечена у абсолютного большинства - 101 пациента, что составило $92 \%$ наблюдений. Сопутствующая ишемическая болезнь сердца (ИБС) диагностирована у 83 больных (75,3\%), причем стенокардия напряжения II-III функционального класса (ФК) отмечена у 65 \% пациентов. У 45 (41 \%) пациентов в анамнезе отмечался перенесенный инфаркт миокарда. Сахарный диабет 2-го типа зафиксирован у 7 (6,3\%) пациентов. Реваскуляризацию миокарда ранее перенесли 26 (23,6 \%) пациентов. У 4 (3,6 \%) пациентов зафиксирован стеноз аортального клапана.

Гемодинамически значимые поражения почечных артерий были выявлены у 6 \% пациентов. У 13 больных $(11,8 \%)$ был диагностирован облитерирующий атеросклероз нижних конечностей, проявлявшийся хронической артериальной недостаточностью I-III степени.

В большинстве случаев клиническое течение основного заболевания носило асимптомный и малосимптомный характер - $91(82,7 \%)$.

Основными показателями эффективности эндоваскулярного лечения в отдаленный период являются отсутствие разрыва аневризмы и сокращение аневризматического мешка.

В связи с риском возникновения эндопротеканий (ЭП), как основного фактора роста аневризматического мешка в отдаленный послеоперационный период, а также миграции или дислокации фрагментов протеза, приводящим к возникновению эндопротеканий $[6,7]$, пациенты после эндопротезирования аорты должны регулярно проходить контрольные обследования на протяжении всей жизни. Нами применен алгоритм наблюдения за пациентами, перенесшими эндопротезирование аорты (рисунок 1).

Результаты и обсуждение. Динамика изменения размера мешка оценивалась по определению средней величины, полученной при измерении продольного, поперечного и максимального диаметров в наиболее широкой его части. При анализе динамики размера аневризматического мешка у 104 больных через 1-3 года у 87 из них отмечено сокращение аневризматического мешка. Стабильным считался размер, изменявшийся в сторону уменьшения или увеличения не более, чем на $5 \%$ от исходного и наблюдался у 12 пациентов, из них у 5 выявлено ЭП II типа. Рост аневризматического мешка за дан- 


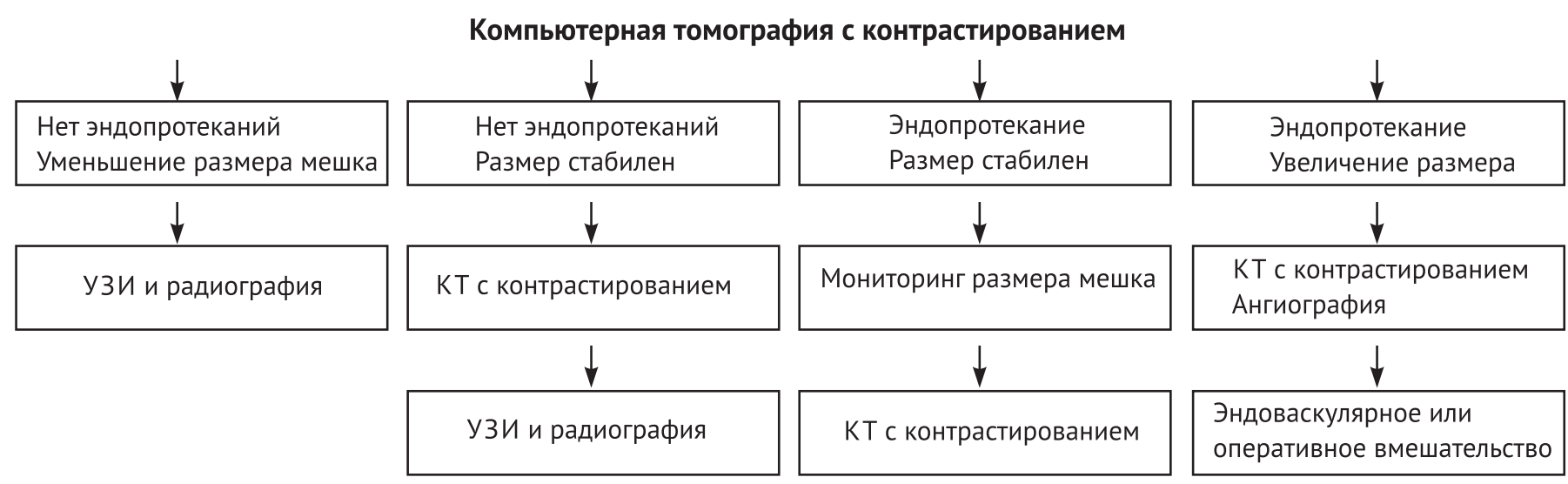

Рисунок 1. Алгоритм отдаленного наблюдения у больных, перенесших эндопротезирование аорты

ный период был отмечен у 7 больных, составил 5-9 \% от исходного размера, в среднем 5,9\%. В данной группе ЭП II типа было выявлено у 3 больных. По поводу эндопротекания III типа у одного больного было предпринято повторное вмешательство в виде имплантации дополнительного удлинителя шейки эндопротеза через 3 месяца после эндопротезирования. При этом размер аневризматического мешка сократился на 5 мм, что составило 8,5 \% от начального размера мешка (54 мм).

При анализе динамики размера аневризматического мешка у 80 больных через 4 года отмечен его стабильный размер - у 13 больных (16,25 \%), причем у 5 из них ЭП были II типа. Рост аневризматического мешка в сравнении с его исходным размером выявлен у 4 больных (5 \%). Рост составил от 4,2 до 15,1\% при наличии ЭП ІІ типа у 3 больных и 28,6 \% у больной с исходным размером 42 мм (через 4 года после операции он увеличился до 54 мм в связи с прогрессированием аневризматического расширения правой общей подвздошной артерии и появлением ЭП ІВ типа).

Более значимыми являются изменения динамики аневризматического мешка в период более 5 лет после вмешательства. При анализе динамики размеров аневризматического мешка у 62 больных через 5-10 лет у 39 (62,9 \%) оставалось выраженным уменьшение аневризматического мешка (от 6,3 до 53,7 \% от исходного размера). В 12 случаях (19,35 \%) состояние аневризматического мешка расценивалось как стабильное и его размер в среднем составил $54 \pm 12$ мм. При этом выявлено ЭП ІІ типа в 5 случаях (рисунок 2).

Увеличилась доля больных с ростом аневризматического мешка, она составила 17,7 \% (11 больных). Значимым увеличение мешка было у одного больного: при исходном размере 59 мм до 80 мм через 10 лет (35,6\%).

Первые 5 лет размер аневризматического мешка был стабильным, его максимальный размер колебался в пределах 57-60 мм (при проведении КТ и УЗИ явного источника протекания выявлено не было).
При этом выраженный рост наблюдался на протяжении 3 месяцев, сопровождался выраженным болевым синдромом и эпизодом желудочно-кишечного кровотечения их верхних отделов желудочно-кишечного тракта. Учитывая быстрый и значимый рост аневризматического мешка, а также выраженную клиническую симтоматику больному была выполнена конверсия - открытая аневризмэктомия, удаление эндопротеза, бифуркационное аллопротезирование.

Во всех остальных случаях увеличение аневризматического мешка не превышало 11,2 \%, было постепенным и не сопровождалось клиническими проявлениями. В 3 случаях было диагностировано персистирующее ЭП II типа, у 4 - появившееся в сроки более 5 лет. У больных с выявленным ростом аневризматического мешка средний его размер составил $51 \pm 9$ мм. Ни в одном случае не выявлено ЭП I или III типов, требовавших повторного вмешательства.

При анализе причин аневризматического роста не выявлено прямой зависимости от исходного размера, наличия дополнительных модулей, возраста или гипертонической болезни.

При подсчете оценочного отношения шансов по Haldane двумя основными факторами, влияющими на рост аневризматического мешка, были наличие эндопротеканий и женский пол.

В ходе проведения работы были изучены морфологические свойства стенки общей бедренной артерии (ОБА) - крупной артерии эластического типа, имеющей близкое строение к стенке аорты. На основании сопоставления полученных данных и отдаленных результатов после эндопротезирования брюшного отдела аорты выявлена возможность прогностической оценки вероятного появления ЭП и динамики размера аневризматического мешка.

Дальнейший статистический анализ показал, что существует устойчивая достоверная связь между характером морфологических изменений в стенке ОБА 


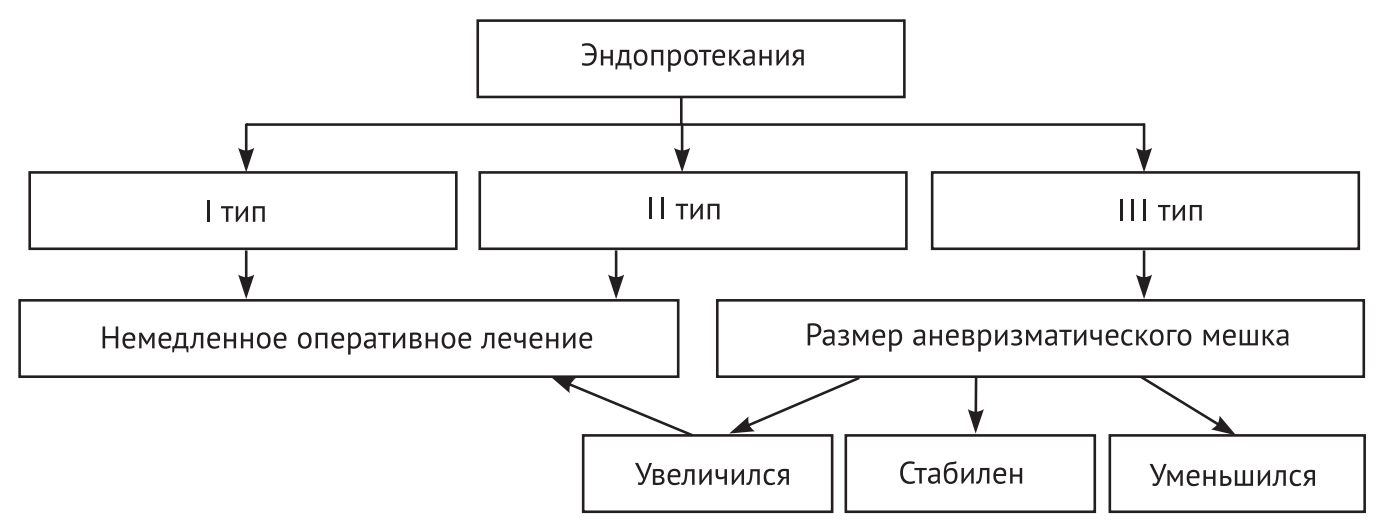

Рисунок 2. Тактика ведения пациента в зависимости от вида выявленного эндопротекания и динамики размера аневризматического мешка

и изменениями размеров аневризматического мешка после проведения эндопротезирования. Для преимущественно атеросклеротических изменений характерно уменьшение объема аневризматического мешка в 77,7 \% случаев, в то время как при дистрофических изменениях без признаков атеросклеротического поражения уменьшение объема аневризматического мешка наблюдается лишь в 28,7 \%, а в 64,2 \% случаев изменения в размерах мешка или отсутствуют, или мешок увеличивается (таблица 1).

Установлено, что при преобладающих атеросклеротических изменениях в стенках сосудов в 16,5 раза $\mathrm{OR}=16,5(2,79-97,68)-$ возрастает вероятность обнаружения благоприятной динамики, а именно уменьшение мешка. При воспалительных процессах данная оценка является неопределенной и статистически не значима. При дистрофических изменениях прогностиобнаружения благоприятной динамики (уменьшение мешка) снижается на $94 \%-\mathrm{OR}=0,06(0,01-0,36)$.

\section{Заключение}

Эндопротезирование брюшного отдела аорты является высокотехнологичной, эффективной и относительно безопасной операцией.

\section{Таблица 1}

Статистическая зависимость динамики размеров аневризматического мешка от типа морфологических изменений в стенке ОБА

\begin{tabular}{lcc}
$\begin{array}{l}\text { Морфологические } \\
\text { данные }\end{array}$ & $\begin{array}{c}\text { Динамика размеров } \\
\text { мешка (\%) }\end{array}$ & $\mathbf{p ~ ( F ) ~}$ \\
\cline { 1 - 2 } Атеросклеротические & $-20,38 \pm 2,79$ & \multirow{2}{*}{$\mathrm{F}=10,32$} \\
\cline { 1 - 2 } Воспалительные & $-10,9 \pm 1,6$ & $\mathrm{p}=0,0003$ \\
\cline { 1 - 2 } Дистрофические & $-0,17 \pm 3,3$ & \\
\hline Всего & $-13,16 \pm 2,52$ & -
\end{tabular}

Больные, перенесшие эндопротезирование аорты, требуют долгосрочного регулярного наблюдения с применением методик как ультразвукового наблюдения, так и компьютерной томографии.

Контроль динамики аневризматического мешка, обнаружение эндопротеканий и своевременная коррекция последних в случае необходимости обеспечивают долгосрочную эффективность операции.

\section{Список использованных источников References}

1. Dingemans SA, Jonker FH, Moll FL, van Herwaarden JA. Aneurysm Sac Enlargement after Endovascular Abdominal Aortic Aneurysm Repair. Ann Vasc Surg. 2016 Feb;31:229-38.

2. Antoniou GA, Georgiadis GS, Antoniou SA, Neequaye S, Brennan JA, Torella F, et al. Late Rupture of Abdominal Aortic Aneurysm After Previous Endovascular Repair: A Systematic Review and Meta-analysis. J Endovasc Ther. 2015 Oct; 22(5):734-44.

3. Candell L, Tucker LY, Goodney P, Walker J, Okuhn S, Hill B, et al. Early and delayed rupture after endovascular abdominal aortic aneurysm repair in a 10-year multicenter registry. J Vasc Surg. 2014 Nov;60(5):1146-53.

4. Zacharias N, Warner CJ, Taggert JB, Roddy SP, Kreienberg $\mathrm{PB}$, Ozsvath KJ, et al. Anatomic characteristics of abdominal aortic aneurysms presenting with delayed rupture after endovascular aneurysm repair. J Vasc Surg. 2016 Dec;64(6):1629-32. https://doi.org/10.1016/j. jvs.2016.04.048. Epub 2016 Jul 16

5. Zandvoort HJ, Gonzalves FB, Verhagen HJ, Werson DA, Moll FL, de Vries JP, et al. Results of endovascular repair of infrarenal aortic aneurysms using the Endurant stent graft. J Vasc Surg. 2014 May;59(5):1195-202. https://doi. org/10.1016/j.jvs.2013.12.031.

6. Hwang D, Park S, Kim HK, Lee JM, Huh S. Reintervention Rate after Open Surgery and Endovascular Repair for Nonruptured Abdominal Aortic Aneurysms. Ann Vasc Surg. 2017 Aug;43:134-43. https://doi.org/10.1016/j.avsg. 2017.03.168 
7. Nolz R, Teufelsbauer H, Asenbaum U, Beitzke D, Funovics M, Wibmer A, et al. Type II endoleaks after endovascular repair of abdominal aortic aneurysms: fate of the aneurysm sac and neck changes during long-term follow-up. J Endovasc Ther. 2012 Apr;19(2):193-9. https://doi. org/10.1583/11-3803.1

\title{
Long-Term Outcomes of Endovascular Aneurysm Repair. Can We Reckon upon a Long-Term Result?
}

\author{
Furkalo S., Nikulnikov P., Khasyanova I., Vlasenko E.
}

Shalimov's National Institute of Surgery and Transplantation to National Academy of Medical Sciences of Ukraine, Kyiv, Ukraine

\begin{abstract}
This article represents the analysis of the long-term outcomes of endovascular treatment of infrarenal aortic aneurysms in 110 patients who underwent endovascular aneurysm repair (EVAR). The age of the patients was $68.5 \pm 9.8$ years, 104 patients were males. Hypertension was noted in the absolute majority - 101 patients, which accounted for $92 \%$ of cases. Concomitant coronary heart disease (CHD) was diagnosed in 83 patients $(75.3 \%)$, and grade II-III stable angina was noted in $65 \%$ of the patients. Forty five $(41 \%)$ patients had a history of myocardial infarction. Type II diabetes mellitus was reported in $7(6.3 \%)$ patients. Previously, 26 (23.6\%) patients had myocardial revascularization. Four (3.6\%) patients had aortic valve stenosis.

In most cases - $91(82.7 \%)$ - the clinical course of the underlying disease was asymptomatic and oligosymptomatic.

The main indicators of EVAR long-term effectiveness are the absence of aneurysm rupture and aneurysmal sac reduction.

Statistical analysis showed stable and reliable relationship between the nature of morphological changes in the femoral artery wall and changes in the size of aneurysmal sac after EVAR. As for atherosclerotic changes, predominant aneurysmal sac reduction was observed in $77.7 \%$ of cases, and only in $28.7 \%$ of cases with dystrophic changes.

Patients undergoing EVAR require long-term regular follow-up using the methods like ultrasound and computerized tomography.

Monitoring of the changes in the aneurysmal sac size, detection of endoleaks and timely correction of the latter, if necessary, ensure long-term effectiveness of the intervention.
\end{abstract}

Keywords: abdominal aortic aneurysm, EVAR, changes in aneurysmal sac size, vascular wall morphology, endoleaks. .

\section{Віддалені результати ендопротезування черевного відділу аорти. Чи можна розраховувати на довгостроковий результат?}

\author{
Фуркало С. М., Нікульников П. І, Хасянова І. В., Власенко О. А. \\ Національний інститут хірургії та трансплантації ім. О. О. Шалімова НАМНУ, м. Київ, Україна
}

Резюме. У статті представлено аналіз довготривалих результатів ендоваскулярного лікування аневризми інфраренального відділу аорти у 110 пацієнтів, які перенесли ендопротезування черевного відділу аорти. Вік хворих становив 68,5 \pm 9,8 року, 104 пацієнта - чоловіки. Артеріальна гіпертензія відзначалася в абсолютній більшості - у 101 пацієнта (92 \% випадків). Супутню ішемічну хворобу серця (IXC) діагностували у 83 хворих (75,3\%), причому стенокардію напруження II-III функціонального класу (ФК) відзначено у 65 \% хворих. У 45 (41\%) пацієнтів в анамнезі відзначали інфаркт міокарда. Цукровий діабет 2-го типу був зареєстрований у 7 (6,3\%) пацієнтів. Раніше 26 (23,6 \%) пацієнтів перенесли реваскуляризацію міокарда. У 4 (3,6 \%) пацієнтів спостерігався стеноз аортального клапана.

У більшості випадків клінічний перебіг основного захворювання був безсимптомним і малосимптомним $91(82,7 \%)$.

Основними показниками ефективності ендопротезування в довгостроковій перспективі є відсутність розриву аневризми і зменшення аневризматичного мішка.

Статистичний аналіз показав, що існує стійкий і надійний зв’язок між характером морфологічних змін у стінці стегнової артерії та змінами розмірів аневризматичного мішка після втручання. Для атеросклеротичних змін переважне зменшення об'єму аневризматичного мішка характерне у 77,7 \% випадків, а при дистрофічних змінах лише у $28,7 \%$.

Пацієнти, які перенесли ендопротезування аорти, вимагають тривалого регулярного спостереження з використанням таких методів, як ультразвук та комп’ютерна томографія.

Контроль за динамікою аневризматичного мішка, виявлення ендопротікань і своєчасна корекція останніх за потреби забезпечують довгострокову ефективність операції.

Ключові слова: аневризма черевної аорти, ендопротезування аорти, динаміка аневризматичного мішка, морфологія судинної стінки, ендопротікання.

Стаття надійшла в редакцію 01.04.2019 р. 